\title{
Article \\ Electrification of Online Ride-Hailing Vehicles in China: Intention Modelling and Market Prediction
}

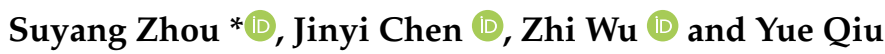 \\ School of Electrical Engineering, Southeast University, Nanjing 210096, China; 220202891@seu.edu.cn (J.C.); \\ zwu@seu.edu.cn (Z.W.); 220182711@seu.edu.cn (Y.Q.) \\ * Correspondence: suyang.zhou@seu.edu.cn
}

Citation: Zhou, S.; Chen, J.; Wu, Z.; Qiu, Y. Electrification of Online Ride-Hailing Vehicles in China: Intention Modelling and Market Prediction. Energies 2021, 14, 7380. https://doi.org/10.3390/en14217380

Academic Editor: Muhammad Aziz

Received: 21 September 2021

Accepted: 1 November 2021

Published: 5 November 2021

Publisher's Note: MDPI stays neutral with regard to jurisdictional claims in published maps and institutional affiliations.

Copyright: (c) 2021 by the authors. Licensee MDPI, Basel, Switzerland. This article is an open access article distributed under the terms and conditions of the Creative Commons Attribution (CC BY) license (https:// creativecommons.org/licenses/by/ $4.0 /)$.

\begin{abstract}
Significant negative impact caused by climate changes, such as economy and life losses, has been experienced globally in recent years, which has called for imminent development and adoption of low carbon technologies in order to mitigate the impact. In 2020, the Chinese government outlined the 'Dual Carbon' Goal where its carbon emission will peak before 2030 whilst China will become 'Carbon Neutral' before 2060. In China, the amount of carbon emissions from the transportation industry stands in second place and it is predicted that the carbon emission of China's automobile industry will reach between 21.5 and 30 billion tons in 2030. Actions should be taken as quickly as possible to facilitate the transition from traditional fossil fuel vehicles to low carbon vehicles such as electric vehicles in order to reduce carbon emissions effectively. Based on the questionnaire that is designed to survey the electrification of online ride-hailing vehicles, this paper first establishes a consumer purchase intention model according to the perceived value theory. By evaluating six aspects including functional value, emotional value, social value, functional risk, financial risk and physical and mental risk, the regression model of the consumer purchase intention for electric vehicles is built. Subsequently, the average operating models for petroleum fuel vehicles, hybrid vehicles and electric vehicles are established, and on top of this, a fossil fuel price model can be derived. This price model can identify from which price it will be advantageous to use electric vehicles to run an online ride-hailing service. Moreover, a multi-agent model is established to illustrate the spread of electric vehicles in the online ride-hailing sector and the private car sector, which is used to predict the trend of the EV market development in China from 2020 to 2040.
\end{abstract}

Keywords: low carbon vehicle; perceived value theory; purchase intention; market diffusion model

\section{Introduction}

Following the severe impact of global warming and air pollution, countries around the world have successively called on the concept of low carbon development and introduced relevant laws and regulations [1]. During the ninth China's Central Finance and Economics Committee Meeting, the goal has been highlighted where China's carbon emission will peak by 2030 and decrease to zero by 2060. The root cause of the excessive carbon emission is the large-scale development and utilization of the fossil resources and the fundamental solution will be to replace fossil energy with the clean energy. The transportation sector is one of the major consumers of oil and statistics from the Internal Energy Agency show that the transportation industry is the second-largest carbon emission entity in the world [2]. In the past decades, the substantial increase in the number of urban cars has led to a significant increase in energy use and greenhouse gas emissions [3], and the rapid growth of private cars has become one of the important factors in environmental pollution and energy consumption [4]. China has the largest number of vehicles being produced and sold, leading to a significant level of carbon emissions. It is estimated that the carbon emissions of China's automobile industry will reach between 21.5 and 30 billion tons in 2030 [5]. To achieve the 'Dual Carbon' Goal, it will be crucial to transform the energy types of the 
automobile industry. In such circumstances, the development of low carbon vehicles has received strong support from governments of various countries and it has drawn extensive attention from researchers [6]. Electric vehicles (EVs) are the most promising low-carbon vehicles [7]. As an important alternative to traditional vehicles with zero exhaust pollution, electric vehicles show great potential in reducing greenhouse gas emissions and solving oil problems [8]. The emergence of EVs can be an important opportunity to change the development direction of China's automobile industry and the EV industry has already obtained enormous support from the Chinese government. Since 2009, China has enforced a series of policies to promote the development of alternative fuel vehicles, especially EVs. However, there are still several obstacles limiting EV adoption, such as the small number of charging stations, short cruising range, and long charging time, etc. In the last decade, ride-hailing services provided by platforms such as Uber have become an important part of the urban mobility landscape worldwide $[9,10]$. Electrification of online ride-hailing vehicles may shed new light on the development of EVs. This paper analyzes the consumer purchase intention model for EVs, identifies from which price it will be advantageous to use electric vehicles to run online ride-hailing services, and predicts the trend of the EV market development in China in the next two decades.

Customers' willingness or intention to purchase electric vehicles is the primary drive for EV consumption. Therefore, it is necessary to investigate the factors that can affect the purchase intention and come up with solutions that can resolve customers' concern in order to effectively promote the development of electric vehicles [11]. At present, the development of China's low carbon automobiles mainly relies on the support of policy and the government and enterprises need to put more effort into marketizing such an emerging industry. Only when the low carbon vehicle industry is market-oriented and in line with customers' requirements can it achieve sustainable development [12]. The investigation of customers' purchase intention can help the government further optimize the high-level policy, make the enterprises further improve market development strategies and change customers' perception and behavior. The cost advantages in daily operation are more obvious for the online ride-hailing drivers, and the electrification of online hailing vehicles can be regarded as the first step to promote the "double replacement" of cars. By analyzing the purchase intention of online ride-hailing drivers, it can provide the government and enterprises with theoretical support for developing relevant policies to guide customers to purchase electric vehicles. In this way, the EV market can transition from a full policydriven mechanism to one that is mainly driven by the market and supported by the policy.

Purchase intention is a customer's overall evaluation of a product when choosing a product and it can be used to describe the likelihood of buying the product. There are many models that can represent the customer purchase intention and they can be categorized into four types: customer attitude theory, customer planning behavior theory, perceived value maximization theory and perceived risk minimization theory. The customer attitude theory is a theory that studies individual behaviors of consumers by investigating how factors such as attitude, subjective consciousness and self-regulation can affect the purchase intention. Some research has shown that the attitude and purchase intention are positively correlated [13]. The second model is the customer planning behavior theory which was first proposed by Ajzen. Researchers have discovered that this theory can predict and explain the behavior of a specific group of people [14]. According to the perceived value maximization theory, there is a positive correlation between customers' perceived value and purchase intention [15] where the perceived value will lead customers to recommend the product to other people around them and make the customer buy the product again [16]. Congmin Sa et al. used perceived value as an intermediate variable to study the relationship between product advertising, corporate brand, consumer reputation and other factors and consumer purchase intention, and confirmed the positive correlation between perceived value and consumer purchase intention. The fourth model is the theory of perceived risk minimization. The perceived risk can be classified into six types: financial risk, functional risk, physical risk, psychological risk, social risk and time risk [17], and these risks can 
decrease customers' purchase intention [18]. Wood in [19] found that perceived value and risk can jointly affect consumers' purchase intention. As the perceived value theory can take both the perceived gains and loss into account, this paper adopts the perceived value theory to investigate factors influencing purchase intention of electric vehicles.

The perceived value theory emerged in the 1980s and it was originally used to solve the problems related to enterprise competition and internal improvement. With its own development and evolution, the perceived value theory was later used to describe customers' evaluation of the value of goods. Researchers in different times, such as Zeithaml and Changhong Bai, believe that customer-perceived value is a utility-oriented evaluation with which the customers assess the benefits and costs associated with the products they purchase $[15,20]$. The perceived value can be classified into four categories according to the number of dimensions. More specifically, the first one is the dichotomy where the perceived value only consists of two dimensions-perceived gain and perceived loss [15]. The perceived gains can be related to different aspects such as perceived quality, individual feeling, commodity attributes, etc., whilst the loss involves financial cost, time cost and spiritual cost. The second category is the tripartition where the perceived values are divided into three dimensions: profit value, experience value and characteristic value [21]. The profit value refers to the gain obtained after using the product, whilst the experience value is the emotional satisfaction that customers obtain from the product. The characteristic value refers to the social and image enhancement effect that the product brings to the users. In the third category, the perceived value is divided into four dimensions, including emotional value, social value, quality value and price value [22]. The final category divides the perceived value into five dimensions; for example, Sheth summarized the five dimensions as social value, emotional value, functional value, cognitive value and environmental value [23]. Other researchers use the aforementioned classification methods of perceived value as the basis and propose new categorization methods for the division of consumer-perceived value dimensions according to their research focus [24,25]. However, none of the aforementioned methods have specifically studied the purchase intention of online ride-hailing drivers to purchase electric vehicles. In addition, there is neglected applicable value to predict the customer purchase behavior by merely relying on the perceived value. This paper uses the theory of perceived value to analyze online ride-hailing drivers' understanding of the risks, profits and related policies of electric vehicles and derive the perceived gain and loss under existing policy framework. Regression analysis is conducted to explore the relationship between perceived value and purchase intention of the online ride-hailing drivers and a purchase intention model is established accordingly. After that, the factors affecting the electrification of online hailing vehicles can be identified, which will be useful for predicting the development of an online ride-hailing service.

The market of alternative fuel vehicles is expanding under government support and enterprise promotion. Studies of the market diffusion of alternative fuel vehicles mainly focus on three aspects: the influence of policy, the research of technology diffusion and the influence of the expanding complementary supporting facilities (e.g., charging facilities). Policies play an important role in customers' choice of new energy vehicles. This can be proved by Struben's research where he built a dynamic model for the alternative energy vehicle market diffusion considering customer preferences and found that the government's long-term political subsidy is an important reason why fuel cell vehicles can occupy the market [26]. Kim et al. in [27] considered the four main participants in the fuel cell market: customers, car manufacturers, operators and the government, and the study showed that if the government can provide appropriate financial subsidy and sufficient infrastructure, fuel cell vehicles are expected to grow and will occupy 33\% of the German market in 2040. It is obvious that the lack of supporting facilities will inevitably prevent customers from purchasing and using alternative fuel vehicles. To address this problem, several researchers have built and investigated the complementary diffusion model between supporting facilities and new energy vehicles. More specifically, Stephan constructed the dynamic utility models for customers and operators and studied the interaction and diffusion of 
fuel cell vehicles and hydrogen refueling stations using the Agent-based method [28]. In the research presented in [29], Patrick E. Meyer established a system dynamics model to study the mutual relationship (i.e., restriction and promotion) between hydrogen vehicles and hydrogen refueling stations. Vehicle adoption rates, infrastructure development rates and hydrogen market conditions are used to explore this phenomenon and the conclusion illustrated that coordinated policies simultaneously encourage the purchase of hydrogen fuel vehicles and the construction of hydrogen fuel infrastructure is the most effective way to quickly establish hydrogen vehicle infrastructure [29]. The studies of the automobile diffusion model for new energy vehicles being reviewed only consider a specific factor such as policy or supporting facility and do not comprehensively investigate the combined effects of multiple factors. This paper establishes a new energy vehicle diffusion model based on the four major factors affecting the diffusion in China's new energy market and analyzes how the future automobile market would develop.

This paper presents a questionnaire-based study on purchase intention and market prediction of electrification of online ride-hailing vehicles in China. Although the research is based on a case study of China, as an efficient approach to reduce fossil fuel utilization and carbon emission, the mode of promoting electric vehicles through electrification of online ride-hailing vehicles can be further generalized and applied in other areas. The methodology of intention modeling and market prediction in this paper will also fill the aforementioned gap in current study. The main content and innovation of this paper can be summarized as below, and the structure of this paper is provided in Figure 1.

1. According to the theory of perceived value, the relationship between perceived gains and losses (as involved in the questionnaire) and customer purchase intentions is first analyzed to establish a customer purchase intention model. Regression analysis will then be applied to the main factors that will affect the online ride-hailing owners to replace their fossil cars with electric vehicles to obtain the function of customer purchase intention.

2. Secondly, the operating costs of online ride-hailing drivers using different types of vehicles (i.e., petroleum, hybrid and electric vehicles) are summarized based on the data obtained from the questionnaire. By comparing the operating costs, and taking into account the expected number of operating years, a fossil fuel price model is derived and it can identify from which price it will be advantageous to use electric vehicles.

3. Finally, a new energy vehicle agent model is established to study the market diffusion mechanism using information from the survey, such as types of customers and the major influencing factors. Combining the current status of China's existing alternative energy vehicle market, the simulation is run to predict the time when a large number of electric vehicles will be used for online car hailing services in an urban area and the time when electric vehicles will be commonly purchased as private cars.

\begin{tabular}{|c|c|c|}
\hline Data Collection & Data Analysis & Research Focus \\
\hline \multirow{2}{*}{$\begin{array}{l}\text { Questionnaire for } \\
\text { Online-Hailing Car } \\
\text { Owners / Drivers }\end{array}$} & Perceived Value Theory & \multirow{2}{*}{$\begin{array}{l}\text { Factors Influencing Purchase Decision and } \\
\text { Function of Purchase Intention }\end{array}$} \\
\hline & Purchase Intention Model & \\
\hline \multirow{3}{*}{$\begin{array}{c}\text { Platform 1: Didi } \\
\text { Drivers of Fossil Fuel } \\
\text { Vehicles }\end{array}$} & General Operating Model & \multirow{3}{*}{$\begin{array}{l}\text { Fossil Fuel Price Model based on Expected } \\
\text { Number of Operating Years }\end{array}$} \\
\hline & of Online-Hailing Vehicle & \\
\hline & \multirow{2}{*}{$\begin{array}{l}\text { General Operating Model } \\
\text { of Electric Vehicle }\end{array}$} & \\
\hline & & \\
\hline \multirow{3}{*}{$\begin{array}{c}\text { Platform 2: Cao Cao } \\
\text { Drivers of Electric } \\
\text { vehicles }\end{array}$} & Customer Types and & \multirow{3}{*}{$\begin{array}{l}\text { Prediction of Market Diffusion for } \\
\text { Alternative Energy Vehicles in Urban Area }\end{array}$} \\
\hline & Major Influencing Factors & \\
\hline & Agent Model & \\
\hline
\end{tabular}

Figure 1. Structure of the paper. 


\section{Data Collection}

\subsection{Selection of Subjects}

Online ride-hailing is a service that people can use to travel to a specific place by reserving the vehicle and destination through an online app or mini program. In China, the ride-hailing service emerged in 2012 and it aims to solve the problem of the coverage of urban public transportation being unable to accommodate the increasing demand for vehicles. Although traditional taxis can still provide service to customers, the number of taxis in urban areas is dwarfed by the number of residents in large cities and thus the travel needs of most people may not be satisfied. In addition, online ride-hailing is commonly regarded as a good example of the sharing economy and has the following unique advantages compared to other ways of travelling: (1) controllability of the user's onboard location and time; (2) visualized driving route and relatively transparent pricing method; (3) measures to improve user experience, such as service evaluation, service supervision, full tracking and back-end payment; (4) use of idle private cars to optimize the allocation of social resources; (5) reduced empty-loaded rate, reduced fuel consumption and increased orders for drivers via unified and optimized scheduling methods. Figure 2 shows the penetration rate of Internet-based transportation in various cities in China in 2018 [30] and Figure 3 shows the number of users of online ride-hailing platforms from 2013 to 2017.

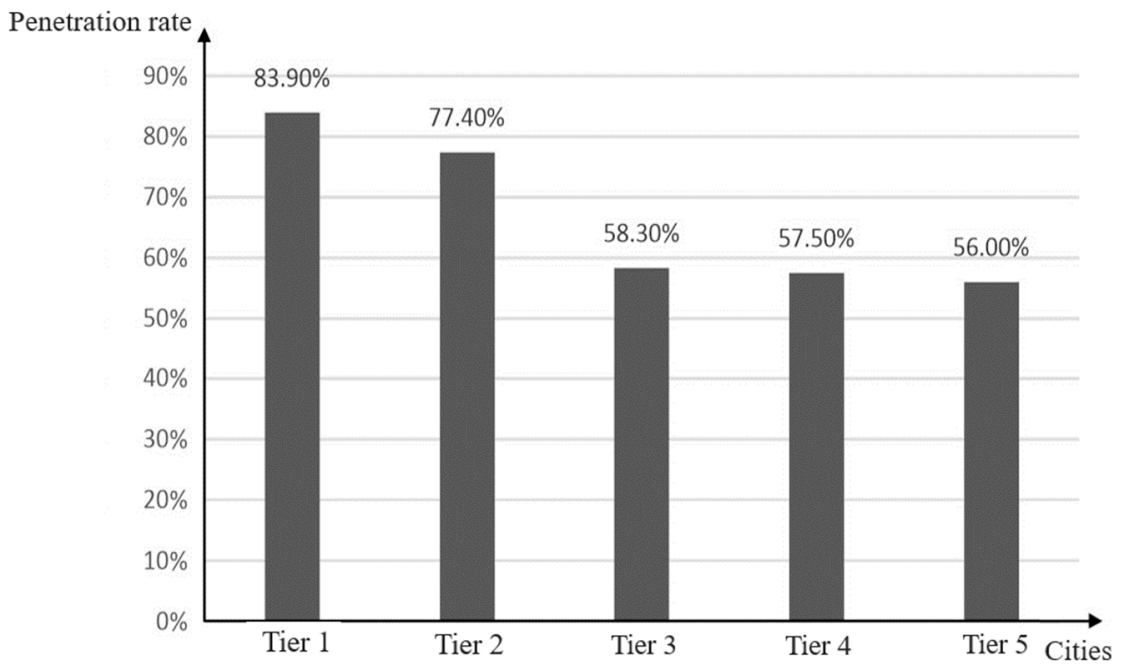

Figure 2. Penetration rate of Internet-based transportation in cities in 2018.

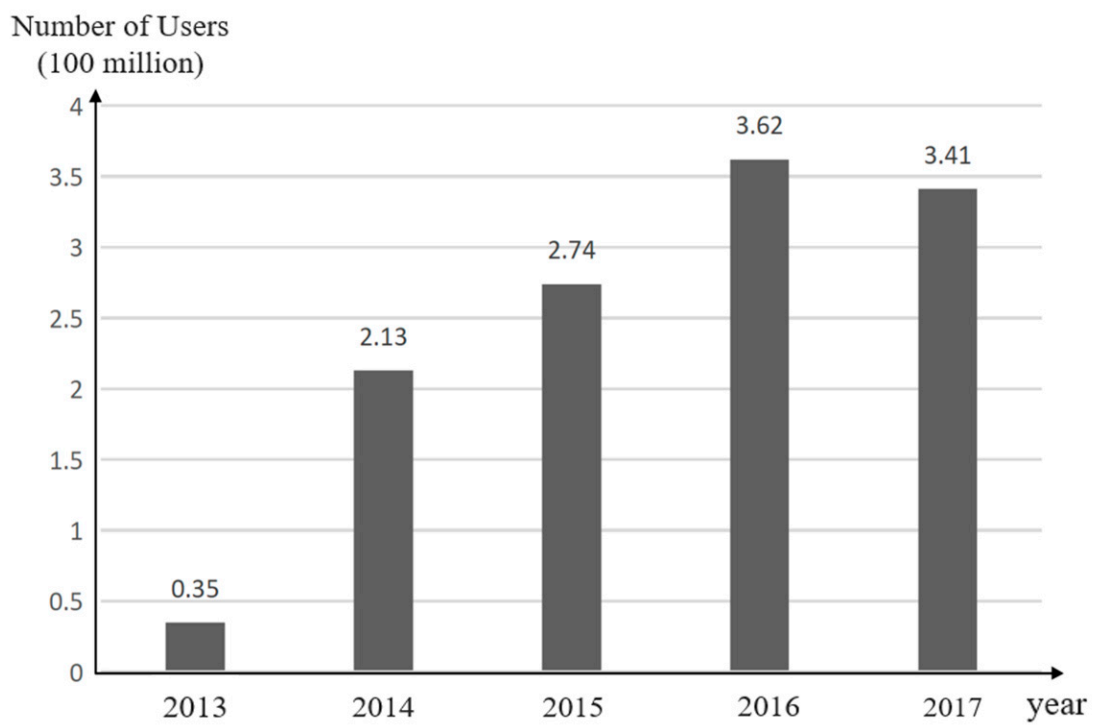

Figure 3. Number of users using online ride-hailing services. 
According to data from the Chinese Ministry of Transport, more than 80 online ridehailing platform companies across the country were granted operating licenses along with more than 340,000 driver licenses and more than 200,000 vehicle transportation licenses being issued across the country by August 2018. As of 31 December 2018, there were five cities with more than 30,000 license plates: Nanjing, Hangzhou, Guangzhou, Shenzhen and Suzhou. Among these cities, Nanjing had the largest number of qualified online ride-hailing vehicles equaling to 42,000 [31]. It can be observed that not only the number of users using the online ride-hailing, but also the quantity of online hailing vehicles is drastically increasing, which suggests that online ride-hailing is an emerging and rapidly developing way of urban transportation. The study of the willingness of online ride-hailing drivers to purchase electric vehicles can be used as a good reference for the urban private car owners when they consider replacing their fossil fuel cars with electric vehicles. It is expected that when the online ride-hailing industry employs electric cars as the primary operating vehicles on a large scale, significant influence will be generated among the private car users.

Similar to the traditional taxi industry, the main purpose of online ride-hailing is to provide passenger service for a certain distance. However, it is more beneficial to study how the online ride-hailing will affect the development of electric vehicles in urban areas due to its special operation pattern. The electrification of traditional taxis is subject to their operating models (contracted operation, operated by a government/state owned enterprise, operated by a private company) and the initiative of taxi electrification is mostly in the hand of the government and enterprises rather than the drivers. There are two possible ways to electrify taxis. One is that the taxi operating companies respond to the government policy and purchase a small number of electric vehicles under the condition that the profitability can still be maintained. The electrification process would be very slow in such circumstances. The other is that the government enforces the replacement of electric taxis. For example, the replacement of traditional fossil fuel taxis was completed within one year in Taiyuan, Shanxi. Researchers in the field of electric vehicles rarely focus on traditional taxis because there is little practical value. Unlike with traditional taxis, the online ride-hailing drivers have a much higher level of flexibility in changing their operating vehicles. Drivers can choose to change their private fossil fuel cars to electric vehicles, which can generate extra income while saving energy and reducing emissions without being restricted by policies. Meanwhile, the group effect formed after the full electrification of online hailing cars can effectively reduce the driving cost of electric vehicles, promote the electrification of vehicles used for other purposes and thus further reduce carbon emissions. Therefore, it will be invaluable to study the electrification of the online hailing vehicles.

Table 1 summarizes the mainstream business models for online ride-hailing platforms including Didi Chuxing, Licheng Zhuanche, Cao Cao Zhuanche, Shouyue Qiche and Shenzhou Zhuanche. The penetration rate of several platforms back in 2017 is shown in Figure 4 . It can be seen that the Didi platform dominated the market with a penetration rate of $58.6 \%$.

This paper selects two online ride-hailing platforms, Didi Chuxing and Cao Cao Chuxing, as the research subjects. Didi Chuxing is chosen because of its longest history, highest penetration rate and largest number of users. It is a representative of the wellestablished online ride-hailing platforms. As the vehicle types of Didi cover gasoline vehicles, hybrid vehicles and gas vehicles, the investigation on Didi mainly focuses on the operating modes of the three types of vehicles and the drivers' intention of purchasing electric vehicles. Whereas, the Cao Cao platform is the first dedicated ride-hailing brand with defined service standard for new energy vehicles. The investigation on Cao Cao can provide us with the basic information for building the operating mode of electric vehicle online hailing services, including the operating costs, benefits, etc. 
Table 1. Business models of online ride-hailing platforms [32].

\begin{tabular}{|c|c|c|c|}
\hline & $\mathrm{C} 2 \mathrm{C}$ & B2C & B2B2C \\
\hline Business model & - & $\begin{array}{l}\text { Dedicated ride-hailing } \\
\text { Licheng Zhuanche, Caocao }\end{array}$ & Aggregated ride-hailing \\
\hline Example platform & Didi Express in early years & $\begin{array}{l}\text { Zhuanche, Shouyue Qiche, } \\
\text { Shenzhou Zhuanche }\end{array}$ & Gaode, etc. \\
\hline Source of drivers & Hiring private car owners & Hiring professional drivers & Travel service provider \\
\hline Number of vehicles & Many & Small number & - \\
\hline Make of vehicles & Various makes and models & Unified make and model & - \\
\hline $\begin{array}{l}\text { Speed for model to be } \\
\text { replicated in a new city }\end{array}$ & Fast & Slow & Slow \\
\hline Asset model & Asset-light & $\begin{array}{c}\text { Mostly asset-heavy and } \\
\text { supplemented with asset-light }\end{array}$ & Asset-light \\
\hline Profit model & $\begin{array}{l}\text { Commission model, big data } \\
\text { value-added, etc. }\end{array}$ & $\begin{array}{l}\text { Self-employment model } \\
\text { (shared income with drivers) }\end{array}$ & - \\
\hline Advantages & $\begin{array}{l}\text { Fast customer acquisition and } \\
\text { easy replication }\end{array}$ & $\begin{array}{l}\text { Unified vehicles and drivers } \\
\text { with high-quality service }\end{array}$ & $\begin{array}{l}\text { Massive scale of users, } \\
\text { network traffic advantages, } \\
\text { map positioning, navigation, } \\
\text { route planning, attract } \\
\text { network traffic for } \\
\text { service provider }\end{array}$ \\
\hline Disadvantages & $\begin{array}{l}\text { Quality variation of drivers } \\
\text { and difficult to control } \\
\text { service quality }\end{array}$ & $\begin{array}{l}\text { Asset-heavy, high-cost, } \\
\text { difficult to replicate quickly } \\
\text { and with insufficient capacity } \\
\text { to attract network traffic }\end{array}$ & $\begin{array}{l}\text { Lower user loyalty compared } \\
\text { to professional travel service } \\
\text { providers and imperfect } \\
\text { one-stop travel } \\
\text { service solution }\end{array}$ \\
\hline Challenges & $\begin{array}{l}\text { Risk of changing and } \\
\text { unexpected policy }\end{array}$ & $\begin{array}{l}\text { Gain of operating license for } \\
\text { dedicated cars, rapid market } \\
\text { expansion and } \\
\text { intense competition }\end{array}$ & $\begin{array}{l}\text { Reliance on map apps, } \\
\text { competition }\end{array}$ \\
\hline
\end{tabular}

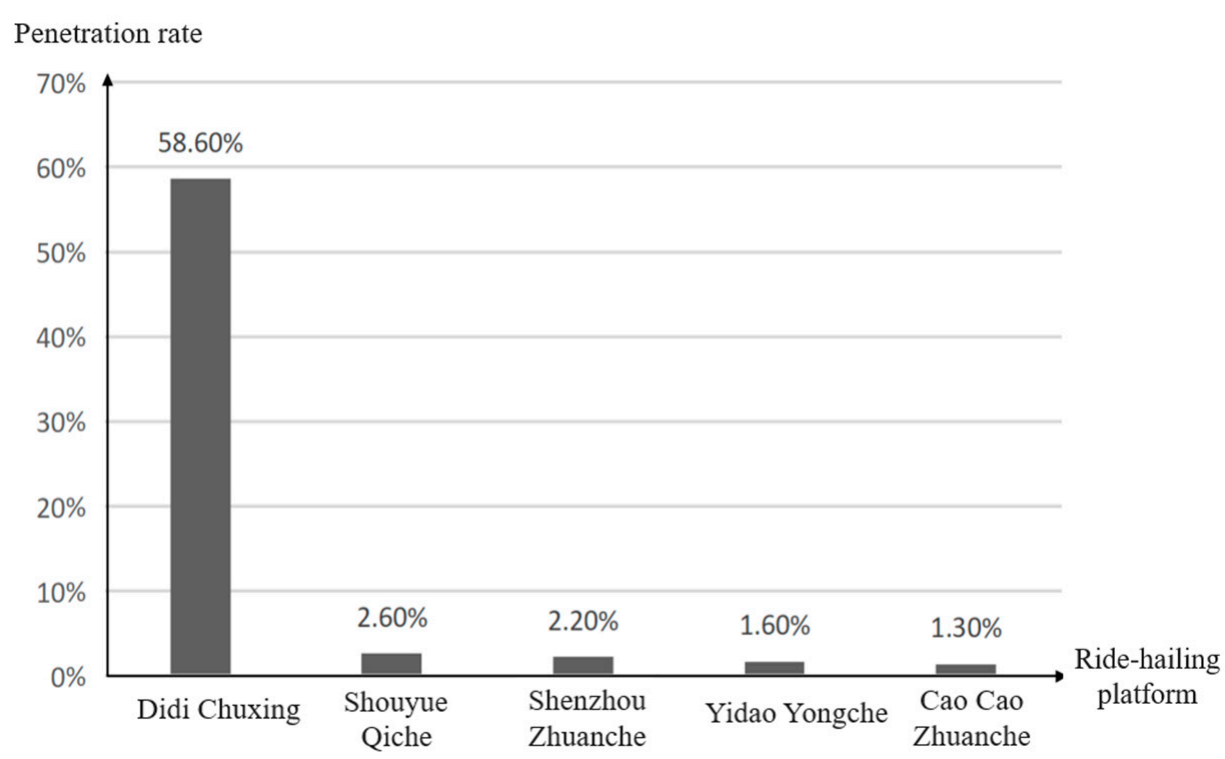

Figure 4. Penetration rate of major online ride-hailing platforms in China in 2017.

\subsection{Questionnaire Design}

This article designs questionnaires for drivers of the two platforms, Didi and Cao Cao. For drivers of Didi, it aimed to collect information that can reflect the purchase intention for electric vehicles and operating information of different types of fossil fuel vehicles. The questionnaire questions include the following aspects: 
(1) Basic information about drivers such as gender, education level, marital status, city of residence, family, children, etc.;

(2) Drivers' hiring history, such as when the driver started driving for online ride-hailing platforms, number of platforms the driver has worked for, monthly income, daily driving hours, number of daily orders, etc.;

(3) Operating vehicle information such as fuel type, daily refueling/recharging times, vehicle ownership, daily mileage, etc.;

(4) Operating costs such as fuel expenditure, annual maintenance costs, annual insurance costs, etc.;

(5) Investigation of driving factors to replace existing cars with electric vehicles, which includes driver's understanding of electric vehicles, intention to change the car, threshold fuel price triggering the change, ideal price of an electric car and the driver's score for the factors that affect the change.

With regard to Cao Cao drivers, the purpose of the questionnaire was to obtain information related to the operating model of electrical vehicles and the operating costs. The content of the questionnaire includes the following aspects:

(1) Basic information about the driver such as gender, education level, marital status, city of residence, family, children, etc.;

(2) Driver's hiring history, such as when the driver started driving for an online ride-hailing platform, number of platforms the driver has worked for, reasons for working for Cao Cao, monthly income, daily driving hours, daily mileage, number of daily orders;

(3) New energy vehicle charging pattern information such as daily charging times, battery range, charging scenarios, whether household charging poles are installed and corresponding reasons, charging period, charging time, charging pole queuing time, minimum charging power, charging time during operation;

(4) The operating costs of new energy vehicles includes the unit cost when using the charging pole, monthly charging cost, annual maintenance cost and annual insurance cost (estimated as zero because Cao Cao will cover it).

Considering that certain Didi drivers may not be aware of the concept of new energy vehicles, a short description for new energy vehicles was inserted at the beginning of the questionnaire designed for Didi drivers. The description provides the definition of new energy vehicles, lists several favorable policies for new energy vehicles, how new energy vehicles are used differently from traditional fossil fuel vehicles and the estimated contribution of electric vehicles to energy conservation and emission reduction. The specific description is shown below.

Electric vehicles are a green, energy-saving and innovative product that can effectively reduce energy consumption and stimulate national economic growth. Since the emerging of the electric vehicle industry, the Chinese government has adopted a series of favourable policies to promote the purchase and use of electric vehicles. For example, the purchase tax of new energy vehicles that is less than $¥ 300,000$ and meets the requirements can be exempted and it is reported that the average subsidy for each vehicle is $¥ 19,000$ in 2020 . Due to the limitations of battery technology at this stage, re-charging is inevitable when electric vehicles travel for long distance. According to various studies, an electric vehicle needs to be charged once per day when it is operated as a passenger vehicle. A single charging cycle normally takes $1.5 \mathrm{~h}$ and costs approximately $¥ 50$ and thus the monthly energy cost is estimated as $¥ 1500$ yuan (electricity subsidy varies with the policy). The monthly expenditure on fuel is cut by approximately $62.5 \%$ compared to the traditional fossil fuel cars.

\subsection{Questionnaire Distribution and Data Collection}

The questionnaires were simultaneously distributed online and offline by a consulting company for five months from 20 April 2019 to 22 September 2019. A total of 950 response copies were collected and 836 were valid, of which 406 out of 427 copies from Cao Cao drivers were valid, whilst 430 out of 523 copies from Didi drivers were valid. The reason 
for choosing Didi drivers is that the Didi platform has the longest history, highest platform penetration rate and largest number of users, which is a good reflection of multiple online ride-hailing platforms on the market. Cao Cao drivers were chosen because the corresponding platform was the first dedicated ride-hailing brand with a defined service standard for new energy vehicles. The data provided by Cao Cao's drivers showing the operating costs and benefits will be useful when building the online ride-hailing operation model where electric vehicles are primarily used. Such a model can provide reference for owners of cars using other types of fuel.

\section{Methodology}

\subsection{Purchase Intention Model for Electric Vehicles Based on Perceived Value Theory}

In the purchase intention model of online ride-hailing vehicle owners for electric vehicles, purchase intention is the dependent variable, while the independent variables are decided according to perceived value theory. Firstly, definitions of the purchase intention and perceived value need to be clarified. According to previous research, there are three common points in the definition of customer purchase intention: (1) Purchase intention is the subjective willingness from the perspective of customer psychology; (2) Purchase intention can predict the likelihood of a customer buying a specific product; (3) There is consistency between purchase intention and purchasing behavior. Thus, this paper defines the purchase intention as the probability of a customer purchasing a product when the customer considers both external and internal factors.

In terms of perceived value, it can be subjective, comparative, hierarchical and dynamic. Based on the classic two-dimension perceived value theory [6], the perceived value can be evaluated from the aspect of perceived gain with positive value and the aspect of perceived loss with negative value. More specifically, perceived gains refers to the direct and indirect benefits that can be obtained by the customer during the time of purchasing a certain product. Considering the possible value of electric vehicles for online ride-hailing drivers, perceived gains can be categorized into ones of functional value, emotional value and social value. The definition of each value is presented below.

- Functional Value: refers to the actual value of the product, which includes the direct benefits of using the product as perceived by the customer.

- Emotional Value: the pleasant experience the customer has when purchasing the product.

- Social Value: refers to the social effect obtained by customers who buy the product.

The perceived loss or loss indicates the direct or indirect loss felt by customers before and after purchasing the product. For online ride-hailing drivers, the most related potential loss can be divided as functional risk, financial risk and physical and mental risk. The definitions are shown below.

- Functional Risk: the risk that the functions of electric vehicles may not meet the expectations.

- Financial Risk: the possible economic loss caused by owning and using electric vehicles.

- Physical and Mental Risk: related to the physical and mental loss that electric vehicles may bring.

The above six aspects based on the perceived value theory together form the six independent variables of the purchase intention model of online ride-hailing vehicle owners, including three aspects of perceived gains (i.e., functional value, emotional value and social value) and three aspects of perceived losses (i.e., functional risk, financial risk and physical and mental risk). The model uses a dependent variable to represent the customer purchase intention and assumes that the government and online ride-hailing platforms provide positive guidance and regulation in encouraging the drivers to buy electric vehicles. A moderating variable is used to observe the actual influence of government and online ride-hailing platforms. Table 2 lists the relevant questions about the purchase intention model in the questionnaire for Didi drivers. The independent variables are measured by a 
5-point Likert scale, where the numbers 1-5 are used to indicate the degree of consent of the interviewees. More specifically, 1 means "strongly disagree" and 5 means "strongly agree".

Table 2. List of model variables and survey questions.

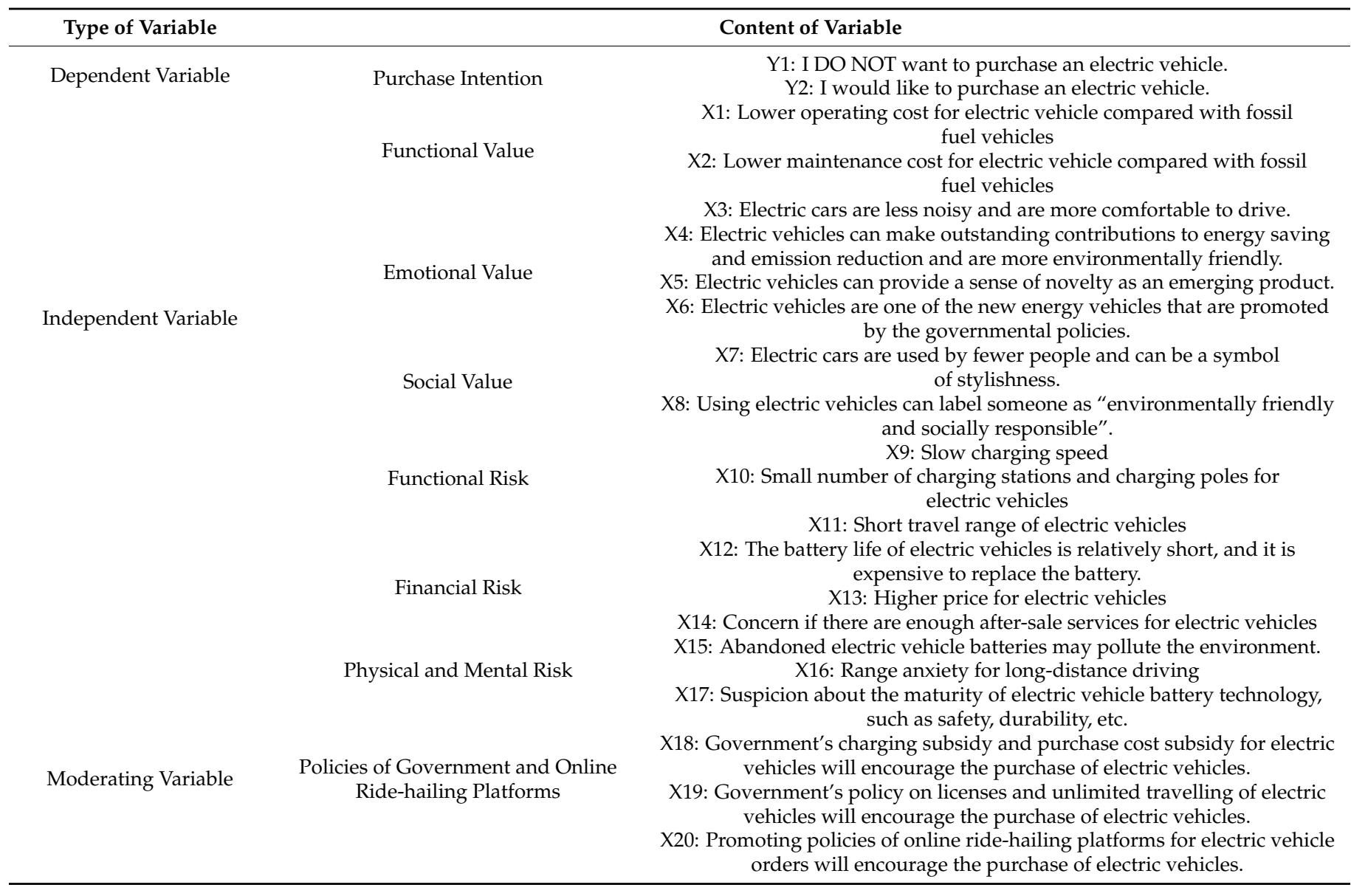

It can be foreseen that the perceived value and purchase intention are positively correlated, whilst the perceived loss and purchase intention are negatively correlated. The supporting policies provided by the government and platforms can affect the purchase intention of online ride-hailing drivers for electric vehicles. Several hypotheses, as shown in Table 3, are proposed in this paper.

Table 3. Hypotheses for the correlation between variables and purchase intention.

\begin{tabular}{ccc}
\hline Hypothesis No. & Variable & Correlation \\
\hline H1 & Perceived Functional Value & Positive correction \\
H2 & Perceived Emotional Value & Positive correction \\
H3 & Perceived Social Value & Positive correction \\
H4 & Perceived Functional Risk & Negative correction \\
H5 & Perceived Emotional Risk & Negative correction \\
H6 & Perceived Physical and Mental Risk & Negative correction \\
H7 & Policy of Government and Platforms & Moderate effect \\
\hline
\end{tabular}

\subsection{Fossil Fuel Price Triggering EV Purchase Based on Average Operating Model of Online Ride-Hailing Car}

Based on the vehicle operating information (i.e., fuel type, daily refueling/recharging times, vehicle ownership, daily mileage), operating cost information (i.e., fuel expenditure, annual maintenance cost, annual insurance cost) and hiring history information (i.e., when the driver started driving for online ride-hailing platform, number of platforms the driver 
has worked for, monthly income, daily driving hours, number of daily orders, etc.) provided by Didi drivers, the average operating model of Didi drivers can be established. Similarly, the hiring history information (i.e., when the driver started driving for an online ride-hailing platform, number of platforms the driver has worked for, the reason for driving for the Cao Cao platform, monthly income, daily driving hours, daily mileage, number of daily orders), charging pattern information of the new energy vehicle (i.e., daily charging times, battery range, charging scenarios, whether household charging poles are installed and corresponding reasons, charging period, charging time, charging pole queuing time, minimum charging power, charging time during operation) and operating cost information (i.e., unit cost when using the charging pole, monthly charging cost, annual maintenance cost and annual insurance cost) obtained from Cao Cao drivers can be used to derive the average operating model when electric vehicles are used as operating vehicles.

The price of gasoline is closely related to the available amount of crude oil and it is expected to follow an upward trend considering the decreasing oil reserve in the future. In such a context, a fuel price model considering the type of vehicles used by online ridehailing drivers and the expected number of operating years is established to identify from which price it will be advantageous to use electric vehicles. The model can be represented by Equation (1):

$$
N_{W D} \times T_{1 \text { day }} \times(1+\Delta p r o f) \times p r o f_{\text {day }} \leq \frac{p r o f_{\text {day }}^{E V} \times N_{W D} \times T_{\text {lday }}-P_{E V}}{Y}
$$

The left part of the expression represents the annual profit of the existing type of vehicles with consideration of expected profit gain. It is worth noting that the annual profit of the vehicle is related to the fuel price. $N_{W D}$ is the number of driving/working days per year and $T_{1 \text { day }}$ is the number of daily driving hours. The expected profit gain is denoted as $\Delta$ prof, whilst prof $f_{d a y}$ indicates the annual profit of a specific type of vehicle (i.e., gasoline and hybrid). The right section of the expression denotes the annual profit of electric vehicles taking into account the purchase cost, where prof $f_{d a y}^{E V}$ is the daily profit of electric vehicle, $P_{E V}$ is the cost of buying the electric vehicle and $Y$ is the expected number of operating years. Information such as number of annual driving days, number of daily driving hours, annual profit and hourly profit of electric vehicles was collected from the drivers. The price of an electric vehicle is assumed to be the average cost when the online ride-hailing drivers purchased their existing electric vehicles. The target gasoline price can be identified when the right session is not less than the left part.

\subsection{Agent-Based Prediction Model for New Energy Vehicle Market Diffusion in an Urban Area}

Agent-Based Modeling and Simulation (ABMS) can describe the changes of a complex system from the micro scale to the macro scale. This section uses the ABMS model to simulate the proliferation of new energy vehicles. The main factors that can affect the spread of China's new energy market include customers, new energy vehicle manufacturers, government policy and charging infrastructure. This paper establishes a new energy vehicle diffusion model and sets up the new energy vehicle agent and customer agent with various attributes and time-varying mechanisms. The new energy vehicle market diffusion model is shown in Figure 5.

From the customer perception model described in Section 3.1, customers are mainly concerned about the price (e.g., retail price, maintenance cost), performance (e.g., travel range, battery life), ease of use (e.g., number of charging facilities) and advantages in environmental protection when considering purchasing electric vehicles. These attributes are assigned to the new energy vehicle agent, and they will change as the natural year advances. More specifically, the model assumes that electric vehicle price will decrease year by year whilst the performance and ease of use will grow. 


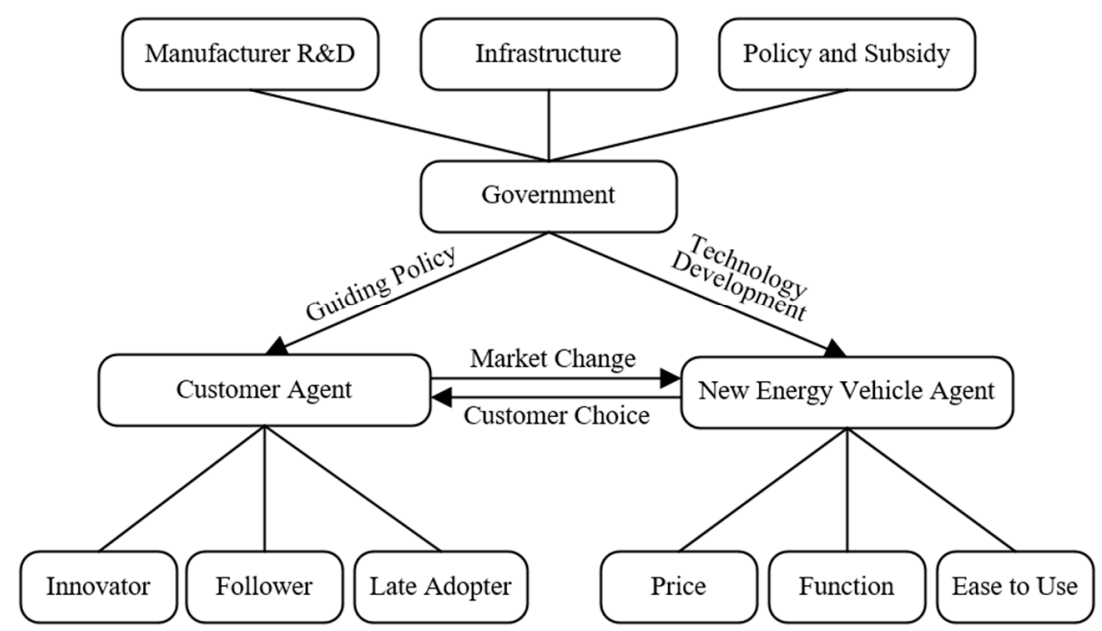

Figure 5. Framework of new energy vehicle market diffusion model.

The group decision can influence the purchase intention of a single customer and such mechanisms between customer groups conform to the small world network structure. Hence, a small world network model of customer agent was built using the NetLogo platform to simulate the effect of product reputation in forming the group decision. Customers were divided into three categories: innovator, follower and late adopter. The innovator customers are the earliest group of people using the new product in the market. This type of customers are not very sensitive to the product price, performance and ease of use and thus are less affected by other customers. However, other types of customers may often be exposed to new products such as electric vehicles because of the innovator customers. The follower customers are highly influenced by others and tend to give priority to product price, performance and other attributes. The late adopter customers generally choose to buy electric vehicles when the market is relatively developed and mature.

\section{Data Analysis and Discussion}

\subsection{Purchase Intention Model for Electric Vehicles Based on Perceived Value Theory}

4.1.1. Validity and Reliability Analysis

\section{- Validity Analysis}

Before analysing the responses to the questionnaire, it is necessary to implement validity analysis to check the validity of the questionnaire. The factor analysis is one of the most effective methods to check the validity. This method is based on the principle of "dimensionality reduction" which categorises variables into different types based on the internal correlation and basic structure between variables and specifies each type of variable as one factor. Subsequently, a few common factors can be used to reflect the information of the original data structure. In general, the KMO value and Bartlett sphericity are used to check whether it is appropriate to conduct the factor analysis for the original data. The KMO value reflects the relationship between the partial correlation coefficient and the simple correlation coefficient of the variable, and a value greater than 0.5 indicates that factor analysis can be implemented.

The SPSS software was used to perform KMO value and Bartlett sphericity test on the collected data and the results are shown in Table 4.

Table 4. KMO value and Bartlett's Sphericity of Electric vehicle Purchase Intention.

\begin{tabular}{ccc}
\hline \multicolumn{2}{c}{ Kaiser-Meyer-Olkin Measure of Sampling Adequacy } & 0.743 \\
\hline Bartlett's Sphericity Test & Approximate Chi Square & 2368 \\
& $\mathrm{df}$ & 132 \\
& Sig. & 0.000 \\
\hline
\end{tabular}


From Table 4, the KMO value is greater than 0.7 and the significance of Bartlett's sphericity test is less than 0.05 , which indicates the validity of the data obtained in this questionnaire for meeting the requirements. After performing the factor analysis, the cumulative variance is $78.654 \%$, exceeding $50 \%$, and it also proves the reliability of the questionnaire data validity.

\section{- Reliability analysis}

The Cronbach's coefficient is commonly used to carry out the reliability analysis whose purpose is to check the internal consistency of data for each variable. The analysis results are listed in Table 5. It can be seen that the Cronbach's coefficient of most variables is greater than 0.7 , suggesting that the reliability of the questionnaire is good. Similarly, the SPSS software was used to analyze the reliability of the questionnaire data.

Table 5. Reliability analysis results of electric vehicle purchase intention.

\begin{tabular}{cccc}
\hline & Variable & Number of Questions & Cronbach's $\alpha$ \\
\hline \multirow{3}{*}{ Perceived Gain } & Functional Value & 3 & 0.786 \\
& Emotional Value & 3 & 0.730 \\
& Social Value & 2 & 0.792 \\
Perceived Loss & Functional Risk & 3 & 0.821 \\
& Financial Risk & 3 & 0.768 \\
& Purchase Intention & 3 & 0.899 \\
& Physical and Mental Risk & 2 & 0.892 \\
\hline
\end{tabular}

The analyses above show that both validity and reliability of the questionnaire data meet the requirements and further data analysis can be carried out.

\subsubsection{Descriptive Statistics}

A data analysis on the basic information of the respondents is conducted. The questionnaires aim to investigate the purchase intention of online ride-hailing drivers (whose existing cars are traditional fossil fuel vehicles using, e.g., petroleum and gas) for electric vehicles and it should be noted that the Cao Cao platform typically distributes the electric vehicles to its drivers. There is thus no assessment of the purchase intention for Cao Cao drivers and the focus of the analysis is on Didi drivers. The basic information of the Didi drivers being surveyed is summarized in Table 6.

Table 6. Statistics of responding Didi drivers.

\begin{tabular}{|c|c|c|c|c|c|}
\hline Variable & Attribute & Pecentage & Variable & Attribute & Percentage \\
\hline \multirow{2}{*}{ Gender } & Male & $82 \%$ & \multirow{2}{*}{ Marital Status } & Unmarried & $11 \%$ \\
\hline & Female & $18 \%$ & & Married & $89 \%$ \\
\hline \multirow{4}{*}{ Age } & $21-30$ & $17 \%$ & \multirow{4}{*}{$\begin{array}{c}\text { Number of Years } \\
\text { Driving for } \\
\text { the Platform }\end{array}$} & Less than 2 years & $74 \%$ \\
\hline & $31-40$ & $39 \%$ & & $2-4$ & $18 \%$ \\
\hline & $41-50$ & $35 \%$ & & $4-6$ & $8 \%$ \\
\hline & $51-60$ & $9 \%$ & & $6-8$ & $0 \%$ \\
\hline \multirow{4}{*}{$\begin{array}{l}\text { Educational } \\
\text { background }\end{array}$} & Junior high school & $18 \%$ & \multirow{4}{*}{$\begin{array}{l}\text { Knowledge of } \\
\text { Electric Vehicles }\end{array}$} & Know very well & $23 \%$ \\
\hline & Senior high school & $51 \%$ & & Know & $56 \%$ \\
\hline & College diploma & $21 \%$ & & Do not know much & $16 \%$ \\
\hline & University and higher & $10 \%$ & & Do not know at all & $5 \%$ \\
\hline
\end{tabular}

From the gender perspective, male drivers accounted for $82 \%$ of the total samples for Didi drivers whilst $18 \%$ were female drivers. Since the questionnaires are un-differentiatedly distributed, this result can roughly indicate that the number of male drivers on the online ride-hailing platform is approximately 4.5 times the number of female drivers.

With regard to age, the Didi platform has the requirement for male drivers to be in the age range of 22-60 and female drivers to be in the range of 22-50. Therefore, the age group between 22 and 60 years old is the focus of the study. In the collected valid samples, 
$74 \%$ of the drivers are in the age group of 31-50 and these people are normally the major labor force for a family. For the marital status, $89 \%$ of the respondents say that they have established a family. It can be inferred that the online ride-hailing drivers are typically the customers who would make expenditures on large household items such as vehicles. Therefore, to investigate the perceived value of these drivers will be useful to identify the level of purchase intention of wider group of people.

In terms of the educational background, people with high-school-level or higher education accounted for $82 \%$ of all respondents. Considering the age distribution of drivers and China's development history, it can be deduced that the respondent Didi drivers tend to have a high educational background and strong environmental awareness and thus will tend to select products that can meet expectations based on their own justification.

For the knowledge of electric vehicles, drivers who know a lot about electric vehicles represent $23 \%$ of the total respondents. Around $56 \%$ have some knowledge, whilst $16 \%$ do not know much about the electric vehicles. Only $5 \%$ of the respondents do not know anything about the electric vehicles. The results show that most drivers have a decent understanding of electric vehicles which could be the result of the joint promotion from government and enterprises in recent years. It is worth noting that only by studying the perceived value of people who have certain level of understanding about electric vehicles can it reflect the true attitude of most people towards electric vehicles.

Table 7 illustrates that drivers using petroleum vehicles have similar opinions to those using gas vehicles with respect to the perceived gains. In general, factors including "X1: Lower operating cost for electric vehicle compared with fossil fuel vehicles", "X2: Lower maintenance cost for electric vehicle compared with fossil fuel vehicles" and "X4: Electric vehicles can make outstanding contributions to energy saving and emission reduction and are more environmentally friendly" are the major reasons why Didi drivers would select electric vehicles. When the online ride-hailing drivers consider the advantages of electric vehicles, they give priority to the operating cost, effectiveness in protecting the environment and maintenance cost. For drivers using petroleum vehicles, the operating cost is the most important perceived gain (percentage of strongly agree and agree reaches $89.34 \%$ ), followed by effectiveness in protecting the environment and governmental promotion. For drivers using gas vehicles, the operating cost is also the most important perceived gain (percentage of strongly agree and agree is $75.18 \%$ ). Unlike drivers using fuel vehicles, they believe that the maintenance cost outweighs the effectiveness in environment protection because the gas vehicles have a low level of carbon emission and the associated pollution can be neglected. By contrast, the online ride-hailing drivers give relatively low scores to the social value, and this shows that people working as online ride-hailing drivers pay more attention to the cost effectiveness and practicality than the added social value.

Regarding the perceived loss, drivers using petroleum vehicles and drivers using gas vehicles have the same concerns for electric vehicles: "X10: Small number of charging stations and charging poles for electric vehicles", "X12: The battery life of electric vehicles is relatively short, and it is expensive to replace the battery", "X13: Higher price for electric vehicles" and "X16: Range anxiety for long distance driving". To sum up, the drivers are mainly concerned about the number and planning of charging stations for electric vehicles, operating costs (i.e., CAPEX and maintenance) and the range of electric vehicles. These factors are closely related to the daily work of drivers. Out of all respondents, $92.48 \%$ of petroleum car drivers and $93.24 \%$ of gas car drivers worry that the range of electric cars will not be sufficient, leading to frequent recharging. However, the number of available charging stations and charging poles for electric cars might be limited and the daily operation can be impacted because the driver cannot find a place to charge during the operation. Looking at existing technologies, a significant amount of time and effort will be needed to resolve the issue of short battery life and high price of electric vehicles and thus these two perceived losses are difficult to be mitigated in a short time. Yet the concern for insufficient number of charging facilities can be resolved by good planning of scale and location in the urban area, which can help promote the adoption of electric vehicles. 
Table 7. Perceived value for Didi drivers of electric vehicles.

\begin{tabular}{|c|c|c|c|c|c|}
\hline Variable & Content of Variable & $\begin{array}{l}\text { Percentage of } \\
\text { Petroleum } \\
\text { Vehicle Drivers } \\
\text { Who Agree and } \\
\text { Strongly Agree }\end{array}$ & $\begin{array}{l}\text { Percentage of } \\
\text { Gas Vehicle } \\
\text { Drivers Who } \\
\text { Agree and } \\
\text { Strongly Agree }\end{array}$ & $\begin{array}{l}\text { Average Degree } \\
\text { of Consent by } \\
\text { Petroleum } \\
\text { Vehicle Drivers }\end{array}$ & $\begin{array}{l}\text { Average Degree } \\
\text { of Consent by } \\
\text { Gas Vehicle } \\
\text { Drivers }\end{array}$ \\
\hline \multirow{3}{*}{$\begin{array}{l}\text { Functional } \\
\text { Value }\end{array}$} & $\begin{array}{l}\text { X1: Lower operating cost for electric vehicle } \\
\text { compared with fossil fuel vehicles }\end{array}$ & $89.34 \%$ & $75.18 \%$ & 4.68 & 4.34 \\
\hline & $\begin{array}{l}\text { X2: Lower maintenance cost for electric } \\
\text { vehicle compared with fossil fuel vehicles }\end{array}$ & $69.25 \%$ & $70.58 \%$ & 4.02 & 4.25 \\
\hline & $\begin{array}{l}\text { X3: Electric cars are less noisy and are more } \\
\text { comfortable to drive. }\end{array}$ & $55.21 \%$ & $56.24 \%$ & 3.32 & 3.47 \\
\hline \multirow[t]{3}{*}{$\begin{array}{l}\text { Emotional } \\
\text { Value }\end{array}$} & $\begin{array}{l}\text { X4: Electric vehicles can make outstanding } \\
\text { contributions to energy saving and emission } \\
\text { reduction and are more } \\
\text { environmentally friendly. }\end{array}$ & $75.29 \%$ & $68.18 \%$ & 4.26 & 3.99 \\
\hline & $\begin{array}{l}\text { X5: Electric vehicles can provide a sense of } \\
\text { novelty as an emerging product. }\end{array}$ & $63.74 \%$ & $60.98 \%$ & 4.03 & 3.85 \\
\hline & $\begin{array}{l}\text { X6: Electric vehicle is one of the new energy } \\
\text { vehicles that are promoted by the } \\
\text { governmental policies. }\end{array}$ & $67.52 \%$ & $60.24 \%$ & 3.45 & 3.26 \\
\hline \multirow[t]{2}{*}{ Social Value } & $\begin{array}{l}\text { X7: Electric cars are used by fewer people and } \\
\text { can be a symbol of stylishness. }\end{array}$ & 49.15 & 42.45 & 3.08 & 2.91 \\
\hline & $\begin{array}{l}\text { X8: Using electric vehicles can label someone } \\
\text { as "environmentally friendly and } \\
\text { socially responsible". }\end{array}$ & $53.38 \%$ & 53.24 & 3.20 & 3.19 \\
\hline \multirow{3}{*}{$\begin{array}{l}\text { Functional } \\
\text { Risk }\end{array}$} & X9: Slow charging speed & $68.24 \%$ & $69.14 \%$ & 3.56 & 3.43 \\
\hline & $\begin{array}{l}\text { X10: Small number of charging stations and } \\
\text { charging poles for electric vehicles }\end{array}$ & $92.48 \%$ & $93.24 \%$ & 4.58 & 4.62 \\
\hline & $\begin{array}{l}\text { X11: Short travel range of electric vehicles } \\
\text { X12: The battery life of electric vehicles is }\end{array}$ & $74.21 \%$ & $72.68 \%$ & 4.02 & 3.97 \\
\hline \multirow{3}{*}{$\begin{array}{l}\text { Financial } \\
\text { Risk }\end{array}$} & $\begin{array}{l}\text { relatively short, and it is expensive to replace } \\
\text { the battery. }\end{array}$ & $76.66 \%$ & $74.34 \%$ & 4.10 & 4.21 \\
\hline & X13: Higher price for electric vehicles & $78.34 \%$ & $79.25 \%$. & 4.38 & 4.52 \\
\hline & $\begin{array}{l}\text { X14: Concern if there are enough after-sale } \\
\text { services for electric vehicles }\end{array}$ & $52.31 \%$ & $54.26 \%$ & 3.21 & 3.14 \\
\hline \multirow{3}{*}{$\begin{array}{l}\text { Physical and } \\
\text { Mental Risk }\end{array}$} & $\begin{array}{l}\text { X15: Abandoned electric vehicle batteries may } \\
\text { pollute the environment. }\end{array}$ & $54.25 \%$ & $5.18 \%$ & 3.15 & 3.17 \\
\hline & $\begin{array}{l}\text { X16: Range anxiety for long-distance driving } \\
\text { X17: Suspicion about the maturity of electric }\end{array}$ & $89.24 \%$ & $88.52 \%$ & 4.51 & 4.50 \\
\hline & $\begin{array}{l}\text { vehicle battery technology, such as safety, } \\
\text { durability, etc. }\end{array}$ & $62.25 \%$ & $63.24 \%$ & 3.68 & 3.75 \\
\hline \multirow{3}{*}{$\begin{array}{l}\text { Policies of } \\
\text { Government } \\
\text { and Online } \\
\text { Ride-hailing } \\
\text { Platforms }\end{array}$} & $\begin{array}{l}\text { X18: Government's charging subsidy and } \\
\text { purchase cost subsidy for electric vehicles will } \\
\text { encourage the purchase of electric vehicles. } \\
\text { X19: Government's policy on licenses and }\end{array}$ & $68.64 \%$ & $72.31 \%$ & 4.02 & 4.13 \\
\hline & $\begin{array}{l}\text { unlimited travelling of electric vehicles will } \\
\text { encourage the purchase of electric vehicles. }\end{array}$ & $58.34 \%$ & $58.42 \%$ & 3.53 & 3.42 \\
\hline & $\begin{array}{l}\text { X20: Promoting policies of online ride-hailing } \\
\text { platforms for electric vehicle orders will } \\
\text { encourage the purchase of electric vehicles. }\end{array}$ & $67.25 \%$ & $68.24 \%$ & 4.23 & 4.15 \\
\hline
\end{tabular}

In terms of the policy, Didi drivers are optimistic about the supporting policies of platforms and government where the percentage of agree and strongly agree for governmental policies are $68.64 \%$ and $72.31 \%$, respectively. The percentage for platforms' policies are $67.25 \%$ and $68.24 \%$, respectively. It should be noted that the governmental subsidy on electric vehicles has been declining in recent years and the electric vehicle industry is gradually evolving to one that is driven by the market rather than the government.

At present, only large densely populated cities such as Beijing, Shanghai, Shenzhen restrict the licensing and travel of traditional fossil vehicles. Electric vehicles are exempt from the traffic restriction policies and thus have drawn significant attention in those mega cities. For customers in other cities, they do not have an urgent need to purchase electric vehicles. Therefore, the average score of factor "X19: Government's policy on licenses and unlimited travelling of electric vehicles will encourage the purchase of electric vehicles" is merely 3.53 and 3.42 for petroleum car drivers and gas car drivers, respectively. 
In addition, the average score of purchase intention of online ride-hailing drivers to purchase electric vehicles is 3.17 and there is a large gap compared to the maximum value of 5 . This suggests that the online ride-hailing drivers are not in urgent need to use electric vehicles. The purchase intention score of petroleum vehicle (including hybrid vehicle) drivers is 3.38 whilst the score of gas vehicle drivers is 2.95 , which indicates that gas vehicle drivers are more conservative and petroleum vehicle drivers are more willing to buy electric vehicles.

In summary, the perceived gain and loss of electric vehicles by petroleum vehicle and gas vehicle drivers are similar. The most important gains for online ride-hailing drivers include low operating cost, environmental protection, energy saving and low maintenance cost. The most common perceived losses are limited number and poor planning of charging stations, high price, high battery maintenance costs and short range of electric vehicles. The policies of government and platforms can also affect the purchase intention.

\subsubsection{Regression Analysis}

The SPSS software is used to perform regression analysis on the respondent data. The regression results show that $R^{2}$ is $0.368, \mathrm{~F}$ is 37.161 and the corresponding significance is 0.000 , which proves that regression analysis is effective. It can be seen from Table 8 that the VIF value is less than 10 and there is thus no multicollinearity in the model variables. Each factor of the perceived gains has a positive regression coefficient with the significance of $t$-test below 0.01 , which indicates a clear correlation between gains. Therefore, the hypotheses $\mathrm{H} 1, \mathrm{H} 2$ and $\mathrm{H} 3$ are valid. Similarly, each factor of the perceived losses has a negative regression coefficient at the level of 0.01 , reflecting a clear correlation between losses. Hence, the hypotheses $\mathrm{H} 4, \mathrm{H} 5$ and $\mathrm{H} 6$ are valid.

Table 8. Regression of perceived values of electric vehicle customers.

\begin{tabular}{|c|c|c|c|c|}
\hline \multirow{2}{*}{ Model } & \multirow{2}{*}{$\begin{array}{c}\text { Normalized } \\
\text { Coefficient }\end{array}$} & \multirow{2}{*}{ Sig. } & \multicolumn{2}{|c|}{ Collinearity Statistics } \\
\hline & & & Tolerance & VIF \\
\hline Functional Value (H1) & 0.430 & 0.000 & 0.733 & 1.341 \\
\hline Emotional Value (H2) & 0.345 & 0.000 & 0.632 & 1.542 \\
\hline Social Value $(\mathrm{H} 3)$ & 0.254 & 0.000 & 0.729 & 1.421 \\
\hline Functional Risk (H4) & -0.143 & 0.001 & 0.834 & 1.210 \\
\hline Financial Risk (H5) & -0.111 & 0.004 & 0.785 & 1.272 \\
\hline Physical and Mental Risk (H6) & -0.110 & 0.004 & 0.863 & 1.108 \\
\hline
\end{tabular}

Based on Table 8, the regression model can be derived as

$$
P=0.430 \times V_{\text {func }}+0.345 \times V_{\text {sent }}+0.254 \times V_{\text {soci }}-0.143 \times R_{\text {func }}-0.111 * R_{\text {fina }}-0.110 \times R_{P \& M}
$$

Equation (2) represents the purchase intention function where P refers to the level of willingness of online ride-hailing drivers to purchase electric vehicles, $V_{f u n c}$ is the functional value, $V_{\text {sent }}$ is the emotional value and $V_{\text {soci }}$ is the social value. In terms of the risks, $R_{f u n c}$ indicates the functional risk, $R_{f i n a}$ indicates the financial risks and $R_{P \& M}$ indicates the physical and mental risks. The purchase intention function expresses the positive correlation between the purchase intention and functional value, emotional value and social value, which means the higher the values are, the stronger the purchase intention will be. Out of the three types of values, the online ride-hailing drivers pay more attention to the functional value of electric vehicles which is whether electric vehicles can bring actual economic benefit. It is obvious that the purchase intention is negatively correlated to functional risk, financial risk and physical and mental risk. The biggest obstacle for drivers to buy electric vehicles is the functional risk including the actual availability of charging facilities, cruising range and battery life. The purchase intention function also shows that the government and electric vehicle companies have to resolve the aforementioned function risks in order to boost the purchase intention for electric vehicles. 


\subsection{Fossil Fuel Price Triggering EV Purchase Based on Average Operating Model of Online Ride-Hailing Car}

The data listed in Table 9 show that the fuel expenditure is one of the major costs for petroleum vehicles and hybrid vehicles. From the survey data, online ride-hailing platforms mainly deploy four types of vehicles involving petroleum vehicles $(79.4 \%)$, hybrid vehicles $(7.8 \%)$, gas vehicles $(6.6 \%)$ and electric vehicles $(6.2 \%)$. Table 9 illustrates that traditional petroleum vehicles have the highest fuel expenditures but earn the least hourly profit. On the contrary, electric vehicles have the lowest fuel expenditures but gain the highest hourly profit, which shows the advantages of electric vehicles. High profitability can be obtained by using gas vehicles but most of the gas vehicles in China are converted from petroleum cars. This can pose a significant safety risk and the Chinese government has published a specific legal document stating that the petroleum-to-gas conversion on vehicles is not allowed anymore, which means that gas vehicles will be banned and will gradually disappear in the online ride-hailing industry. Therefore, this paper does not focus on the gas price that can trigger the purchase of electric vehicles.

Table 9. Revenue and cost for Didi drivers and Cao Cao drivers.

\begin{tabular}{|c|c|c|c|c|c|}
\hline Vehicle Type & $\begin{array}{c}\text { Average Annual } \\
\text { Fuel Expenditure } \\
\text { (¥) }\end{array}$ & $\begin{array}{c}\text { Average Annual } \\
\text { Maintenance and } \\
\text { Insurance Cost (Incl. } \\
\text { Subsidy) } \\
(¥)\end{array}$ & $\begin{array}{l}\text { Average Annual } \\
\text { Income } \\
(¥)\end{array}$ & $\begin{array}{c}\text { Average Annual } \\
\text { Profit } \\
(¥)\end{array}$ & $\begin{array}{c}\text { Average Hourly } \\
\text { Profit } \\
(¥ / \mathbf{h})\end{array}$ \\
\hline $\begin{array}{c}\text { Didi Driver } \\
\text { (Hybrid Vehicle) }\end{array}$ & 36,572 & 8302 & 125,420 & 80,546 & 29.83 \\
\hline $\begin{array}{c}\text { Didi Driver } \\
\text { (Gasoline Vehicle) }\end{array}$ & 48,803 & 8247 & 121,363 & 72,560 & 26.87 \\
\hline $\begin{array}{l}\text { Didi Driver } \\
\text { (Gas Vehicle) }\end{array}$ & 35,402 & 8050 & 126,542 & 83,090 & 30.77 \\
\hline $\begin{array}{l}\text { Cao Cao Driver } \\
\text { (Electric Vehicle) }\end{array}$ & 18,000 & 0 & 105,815 & 87,815 & 32.52 \\
\hline
\end{tabular}

Based on the operating information presented in Table 10 and the fuel price model established in Section 3.2, the fuel price triggering EV purchase can be calculated. Table 11 shows the difference between the derived gasoline price and drivers' expected price for triggering the purchase of electric vehicle. From Table 11, it can be seen that drivers' expected gasoline price is higher than the derived price when gasoline vehicles are used whilst the price estimated by drivers of hybrid vehicles is lower than the calculated value. This reflects the fact that drivers using hybrid vehicles are more conservative about changing vehicles than those using gasoline vehicles, and more conditions have to be satisfied to trigger the purchase of electric vehicle. This is because the operating cost of hybrid vehicles is lower than that of gasoline vehicles and most hybrid vehicles have been purchased not long ago. Considering that the hybrid vehicles are relatively new and still in good condition, owners tend to be reluctant to purchase new electric vehicles. Therefore, it can be expected that the electric vehicles will mainly replace the gasoline vehicles and the hybrid vehicle drivers will be less enthusiastic to embrace the electric vehicle market.

Table 10. Operating information of Didi and Cao Cao vehicles.

\begin{tabular}{ccccc}
\hline Vehicle Type & $\begin{array}{c}\text { Average Number } \\
\text { of Daily Orders }\end{array}$ & $\begin{array}{c}\text { Average Daily } \\
\text { Mileage }\end{array}$ & $\begin{array}{c}\text { Time spent for } \\
\text { Refueling/Recharging }\end{array}$ & $\begin{array}{c}\text { Number of } \\
\text { Refueling/Recharging } \\
\text { Times }\end{array}$ \\
\hline Didi Driver (Hybrid Vehicle) & 26 & $255 \mathrm{~km}$ & $5 \mathrm{~min}$ & 1 \\
Didi Driver (Gasoline Vehicle) & 25 & $238 \mathrm{~km}$ & $5 \mathrm{~min}$ & 1 \\
Didi Driver (Gas Vehicle) & 26 & $249 \mathrm{~km}$ & $10 \mathrm{~min}$ & 2 \\
Cao Cao Driver (Electric Vehicle) & 24 & $215 \mathrm{~km}$ & $150 \mathrm{~min}$ & 2 \\
\hline
\end{tabular}


Table 11. Comparison between calculated gasoline price and drivers' expected gasoline price triggering EV purchase.

\begin{tabular}{ccc}
\hline $\begin{array}{c}\text { Expected Number of } \\
\text { Driving Years }\end{array}$ & $\begin{array}{c}\text { Gasoline Price for Gasoline } \\
\text { Vehicle (Difference from } \\
\text { Drivers' Expected Gasoline } \\
\text { Price) }(¥ / \mathrm{L})\end{array}$ & $\begin{array}{c}\text { Gasoline Price for Hybrid } \\
\text { Vehicle (Difference from } \\
\text { Drivers’ Expected Gasoline } \\
\text { Price) }(¥ / \mathrm{L})\end{array}$ \\
\hline 5 Years & $9.017(+0.483)$ & $10.397(-1.097)$ \\
10 Years & $8.175(+1.35)$ & $9.556(-0.256)$ \\
15 Years & $7.895(+1.605)$ & $8.275(-0.125)$ \\
\hline
\end{tabular}

\subsection{Agent-Based Prediction Model for New Energy Vehicle Market Diffusion in Urban Areas}

The results of the questionnaire show that the proportion of the innovator, follower and late adopter customers amongst online ride-hailing drivers is $5 \%, 69 \%$ and $26 \%$, respectively. The drivers were also asked to rate the level of importance of each electric vehicle attribute (i.e., price, performance and ease of use) when doing the surveys and these results are compiled using the analytic hierarchy process to obtain the weight of each electric vehicle attribute for customers' decision making, as shown in Table 12. In order to compare with the private car market, the percentage for each type of customer (i.e., innovator, follower, late adopter) and the weight of electric vehicle attributes are specified for the private car drivers using data from studies of other researchers. The related data are listed in Table 13.

Table 12. Weight of electric vehicle attributes for online ride-hailing drivers.

\begin{tabular}{ccccc}
\hline $\begin{array}{c}\text { Type of } \\
\text { Customer }\end{array}$ & Percentage & Weight of Price & $\begin{array}{c}\text { Weight of } \\
\text { Performance }\end{array}$ & $\begin{array}{c}\text { Weight of Ease } \\
\text { of Use }\end{array}$ \\
\hline Innovator & $5 \%$ & 0.2821 & 0.4521 & 0.2658 \\
Follower & $69 \%$ & 0.3581 & 0.4210 & 0.2209 \\
Late Adopter & $26 \%$ & 0.3842 & 0.3210 & 0.2948 \\
\hline
\end{tabular}

Table 13. Weight of electric vehicle attributes for private car drivers.

\begin{tabular}{ccccc}
\hline $\begin{array}{c}\text { Type of } \\
\text { Customer }\end{array}$ & Percentage & Weight of Price & $\begin{array}{c}\text { Weight of } \\
\text { Performance }\end{array}$ & $\begin{array}{c}\text { Weight of Ease } \\
\text { of Use }\end{array}$ \\
\hline Innovator & $9 \%$ & 0.2268 & 0.5463 & 0.2268 \\
Follower & $48 \%$ & 0.4000 & 0.4000 & 0.2000 \\
Late Adopter & $43 \%$ & 0.4999 & 0.2501 & 0.2500 \\
\hline
\end{tabular}

Figure 6 shows the ABMS simulation results for the market share of electric vehicles in online ride-hailing and private car sectors. It can be seen that the percentage of electric vehicles used in online ride-hailing service will reach $20 \%, 50 \%, 80 \%$ by the years 2023 , 2025 and 2028, respectively, while for the private car sector it will be the year of 2025, 2028 and 2032, respectively. This indicates that the electrification of online ride-hailing vehicle will be ahead of the private car because there is larger proportion of follower customers among the online ride-hailing drivers leading to faster adoption of electric vehicles. It is worth noting that the percentage of electric vehicles used in online ride-hailing services will reach $100 \%$ in 2034 and the market share of electric vehicles in the private car sector will reach $100 \%$ in 2038, which means that the market share of traditional fossil fuel cars will gradually decline in the next two decades and eventually disappear from the market. This is in line with the development expectation of the future automobile market. Since the model only considers electric vehicles and traditional fossil fuel vehicles, the market share of electric vehicles will inevitably reach $100 \%$ over time. However, there will be a variety of vehicle types in the future automotive market and the market share of electric vehicles would be lower compared to the values calculated by the model. 


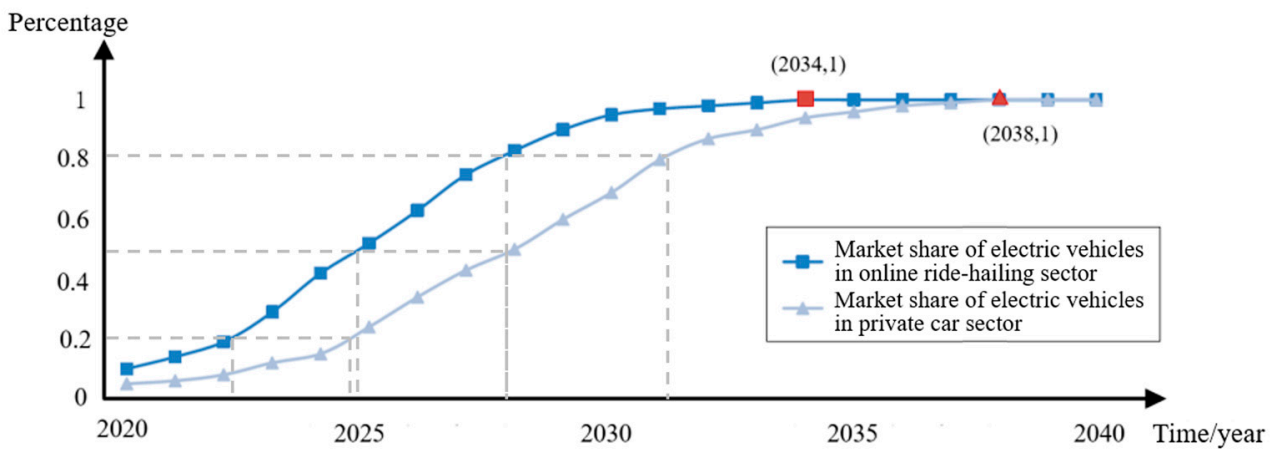

Figure 6. ABMS simulation result: market share of electric vehicles in online ride-hailing and private car sectors.

\section{Conclusions}

This paper conducts questionnaire-based research on two mainstream online ridehailing platforms in China, and three models are established based on the collected data to analyze the possibility to electrify the online hailing vehicles from perspective of purchase intention, operating costs of different types of vehicles and diffusion mechanism of the electric vehicle market. The main findings of this paper are summarized below.

1. The average score of purchase intention of online ride-hailing drivers to purchase electric vehicles is 3.17 and there is a large gap compared to the maximum value of 5 , indicating that the online ride-hailing drivers are not in urgent need to use electric vehicles.

2. The purchase intention score of petroleum vehicle (including hybrid vehicle) drivers is 3.38 whilst the score of gas vehicle drivers is 2.95 , which indicates that gas vehicle drivers are more conservative and petroleum vehicle drivers are more willing to buy electric vehicles.

3. According to the function of purchase intention of ride-hailing drivers for EVs, there is a positive correlation between the purchase intention and the perceived gains (i.e., functional value, emotional value and social value), and a negative correlation to the perceived loss (i.e., functional risk, financial risk and physical and mental risk). Lower charging cost (compared with refueling cost), lower maintenance cost and effectiveness of electric vehicles in environmental protection are the most attractive advantages for the online ride-hailing drivers. The most discouraging perceived losses are insufficient charging infrastructure, mileage anxiety, high retail price and short battery life. In order to promote the electrification of online hailing vehicles, it is necessary to mitigate the impact of the aforementioned perceived losses whilst enhancing the benefits from the perceived gains.

4. From the average operating model of gasoline vehicles, hybrid vehicles and electric vehicles, it can be observed that when the driver expects to use the vehicle for 15 years or more, the gasoline price triggering EV purchase for gasoline vehicle drivers is 7.895 yuan per liter whilst the trigger gasoline price for hybrid vehicles is 8.275 yuan per liter.

5. A multi-agent model is built to predict the spread of electric vehicle in online ridehailing sector and the private car sector. Combined with the future development trend, a small-world network is used to represent customers' decision-making mechanism and simulate the status of online ride-hailing market and private car market between 2020 and 2040 in China. The simulation results show that the electric vehicle diffusion in the online ride-hailing sector will occur earlier than in the private car sector. When there are only electric vehicles and traditional fossil fuel vehicles, the percentage of electric vehicles used in online ride-hailing service will reach 100\% in 2034 and the market share of electric vehicles in the private car sector will reach $100 \%$ in 2038 , which means that the market share of traditional fossil fuel cars will gradually decline in the next two decades and eventually disappear from the market. This is in line with the development expectation of the future automobile market. 
Author Contributions: Conceptualization, S.Z. and Z.W.; methodology, J.C.; writing-original draft preparation, J.C.; writing - review and editing, Y.Q. All authors have read and agreed to the published version of the manuscript.

Funding: This research was funded by National Nature Science Foundation of China with grant number 51807024 .

Institutional Review Board Statement: Ethical review and approval were waived for this study, due to the questionnaire investigation conducted in this study does not include any ethical problems, and the subjects of the investigation are ensured confidentiality and anonymity.

Informed Consent Statement: Informed consent was obtained from all subjects involved in the study.

Conflicts of Interest: The authors declare no conflict of interest.

\section{References}

1. Zhang, X.; Zhao, H.; Zhou, X. The Development and Problems of China's New-Energy Auto Industry: Based on the Perspective of Sustainable Development of Auto Industry. Theory Mod. 2011, 2, 60-66.

2. Ding, J. Analysis on carbon emission and emission reduction potential of transportation industry in China. China Transp. Rev. 2012, 12, 20-26.

3. Du, H.; Liu, D.; Southworth, F.; Ma, S.; Qiu, F. Pathways for energy conservation and emissions mitigation in road transport up to 2030: A case study of the Jing-Jin-Ji area, China. J. Clean. Prod. 2017, 162, 882-893. [CrossRef]

4. Wang, Z.; Dong, X. Determinants and policy implications of residents' new energy vehicle purchases: The evidence from China. Nat. Hazards 2016, 82, 155-173. [CrossRef]

5. Yang, S.; Cheng, P.; Li, J.; Wang, S. Which group should policies target? Effects of incentive policies and product cognitions for electric vehicle adoption among Chinese consumers. Energy Policy 2019, 135, 111009.

6. Tushar, W.; Yuen, C.; Huang, S.; Smith, D.B.; Poor, H.V. Cost minimization of charging stations with photovoltaics: An approach with EV classification. IEEE Trans. Intell. Transp. Syst. 2016, 17, 156-169.

7. Labatt, S.; White, R.R. Carbon finance: The financial implications of climate change. Hoboken. TERI Inf. Dig. Energy Environ. 2007, 6, 409 .

8. Zhou, S.; Zhuang, Y.; Gu, W.; Wu, Z. Operation and Economic Assessment of Hybrid Refueling Station Considering Traffic Flow Information. Energies 2018, 11, 1991. [CrossRef]

9. Jiao, Y.; Tang, X.; Qin, Z.T.; Li, S.; Zhang, F.; Zhu, H.; Ye, J. Real-world ride-hailing vehicle repositioning using deep reinforcement learning. Transp. Res. Part C Emerg. Technol. 2021, 130, 103289.

10. Mao, H.; Deng, X.; Jiang, H.; Shi, L.; Li, H.; Tuo, L.; Shi, D.; Guo, F. Driving safety assessment for ride-hailing drivers. Accid. Anal. Prev. 2021, 149, 105574. [CrossRef]

11. Guerra, E. Electric vehicles, air pollution, and the motorcycle city: A stated preference survey of consumers' willingness to adopt electric motorcycles in Solo, Indonesia. Transp. Res. Part D Transp. Environ. 2019, 68, 52-64. [CrossRef]

12. Plenter, F.; von Hoffen, M.; Chasin, F.; Benhaus, S.; Matzner, M.; Paukstadt, U.; Becker, J. Quantifying Consumers' Willingness to Pay for Electric Vehicle Charging. In Proceedings of the 20th IEEE Conference on Business Informatics (CBI), Vienna, Austria, 11-13 July 2018.

13. Chen, M. Consumer attitudes and purchase intentions in relation to organic foods in Taiwan: Moderating effects of food-related personality traits. In Proceedings of the International Symposium on China's Organic Food Market and Development, Shanghai, China, 24-26 May 2009.

14. Ma, Y. The Influence of the Conflict of Online Reviews on Consumer Attitudes. Econ. Probl. 2014, 3, 37-40.

15. Zeithaml, V.A. Consumer Perceptions of Price, Quality, and Value: A Means-End Model and Synthesis of Evidence. J. Mark. 1988, 52, 2. [CrossRef]

16. Thielemann, V.M.; Ottenbacher, M.C.; Harrington, R.J. Antecedents and consequences of perceived customer value in the restaurant industry: A preliminary test of a holistic model. Int. Hosp. Rev. 2018, 32, 26-45. [CrossRef]

17. Gao, H. Research on components of consumer perceived risk. In Proceedings of the 2006 IEEE International Engineering Management Conference, Salvador, Brazil, 17-20 September 2006.

18. Featherman, M.S.; Pavlou, P.A. Predicting e-services adoption: A perceived risk facets perspective. Int. J. Hum. Comput. Stud. 2003, 59, 451-474. [CrossRef]

19. Wood, C.M.; Scheer, L.K. Incorporating perceived risk into models of consumer deal assessment and purchase intent. Adv. Consum. Res. 1996, 23, 399-404.

20. Bai, C. Literature Review of Customer Value and Its Implications. Nankai Bus. Rev. 2001, 2, 51-55.

21. Holbrook, M.B.; Schindler, R.M. Age, Sex, and Attitude toward the past as Predictors of Consumers' Aesthetic Tastes for Cultural Products. J. Mark. Res. 1994, 31, 412.

22. Sweeney, J.C.; Soutar, G.N. Customer perceived value: The development of a multiple item scale. J. Retail. 2001, 77, 203-220. [CrossRef] 
23. Sheth, J.N.; Newman, B.I.; Gross, B.L. Why We Buy What We Buy: A Theory of Consumption Values: Discovery Service for Air Force Institute of Technology. J. Bus. Res. 1991, 22, 159-170. [CrossRef]

24. Chen, Q. Factual Dimensions of University Students' Perceived Value Based on Grounded Theory. Chin. J. Manag. 2011, 7, 1021-1026, 1066.

25. Hong, J.-C.; Lin, P.-H.; Hsieh, P.-C. The effect of consumer innovativeness on perceived value and continuance intention to use smartwatch. Comput. Hum. Behav. 2017, 67, 264-272.

26. Struben, J.; Sterman, J.D. Transition challenges for alternative fuel vehicle and transportation systems. Environ. Plan. B Plan. Des. 2008, 35, 1070-1097. [CrossRef]

27. Kim, J.; Moon, I. The role of hydrogen in the road transportation sector for a sustainable energy system: A case study of Korea. Int. J. Hydrogen Energy 2008, 33, 7326-7337. [CrossRef]

28. Stephan, C.; Sullivan, J. An agent-based hydrogen vehicle/infrastructure model. In Proceedings of the Congress on Evolutionary Computation, Portland, OR, USA, 19-23 June 2004.

29. Meyer, P.E.; Winebrake, J.J. Modeling technology diffusion of complementary goods: The case of hydrogen vehicles and refueling infrastructure. Technovation 2009, 29, 77-91.

30. Analysis on the Penetration Rate of China's Online Car Hailing Cities, Industry Platform Penetration, Industry Demand, Satisfaction and Industry Development Trend in 2018. Available online: https:/ /www.chyxx.com/industry/201811/690210.html (accessed on 8 November 2018).

31. 127 Ranking List of Car Hailing Compliance of Urban Network. Available online: https://www.sohu.com/a/288232766_100163 866 (accessed on 11 January 2019).

32. Wilson: Development Status and Prospect of Online Car Hailing Market. Available online: https://baijiahao.baidu.com/s?id=16 62141734070688791\&wfr=spider\&for=pc (accessed on 26 March 2020). 